San Jose State University

SJSU ScholarWorks

Master's Theses

Master's Theses and Graduate Research

1995

\title{
Barriers that prevent older women from performing Breast Self- Examinations
}

Christine M. Derenzi

San Jose State University

Follow this and additional works at: https://scholarworks.sjsu.edu/etd_theses

\section{Recommended Citation}

Derenzi, Christine M., "Barriers that prevent older women from performing Breast Self-Examinations" (1995). Master's Theses. 988.

DOI: https://doi.org/10.31979/etd.uvnd-845x

https://scholarworks.sjsu.edu/etd_theses/988

This Thesis is brought to you for free and open access by the Master's Theses and Graduate Research at SJSU ScholarWorks. It has been accepted for inclusion in Master's Theses by an authorized administrator of SJSU ScholarWorks. For more information, please contact scholarworks@sjsu.edu. 


\section{INFORMATION TO USERS}

This manuscript has been reproduced from the microfilm master. UMI films the text directly from the original or copy submitted. Thus, some thesis and dissertation copies are in typewriter face, while others may be from any type of computer printer.

The quality of this reproduction is dependent upon the quality of the copy submitted. Broken or indistinct print, colored or poor quality illustrations and photographs, print bleedthrough, substandard margins, and improper alignment can adversely affect reproduction.

In the unlikely event that the author did not send UMI a complete manuscript and there are missing pages, these will be noted. Also, if unauthorized copyright material had to be removed, a note will indicate the deletion.

Oversize materials (e.g., maps, drawings, charts) are reproduced by sectioning the original, beginning at the upper left-hand corner and contiming from left to right in equal sections with small overlaps. Each original is also photographed in one exposure and is included in reduced form at the back of the book.

Photographs included in the original manuscript have been reproduced xerographically in this copy. Higher quality $6^{\prime \prime} \times 9^{n}$ black and white photographic prints are available for any photographs or illustrations appearing in this copy for an additional charge. Contact UMI directly to order.

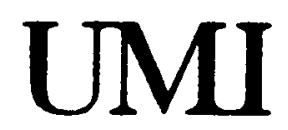

A Bell \& Howell information Company

300 North Zeeb Road. Ann Arbor. MI 48106-1346 USA

$313.761-4700 \quad 800: 521-0600$ 



\title{
A Thesis
}

Presented to

The Faculty of the School of Nursing

San Jose State University

\author{
In Partial Fulfillment \\ of the Requirements for the Degree \\ Master of Science
}

By

Christine M. Derenzi

May, 1995 
UMI Number: 1374579

Copyright 1995 by

Derenzi, Christine Marie

All rights reserved.

UMI Microform 1374579

Copyright 1995, by UMI Company. All rights reserved.

This microform edition is protected against unauthorized copying under Title 17, United States Code.

\section{UMI}

300 North zeeb Road

Ann Arbor, MI 48103 
APPROVED FOR THE SCHOOL OF NURSING

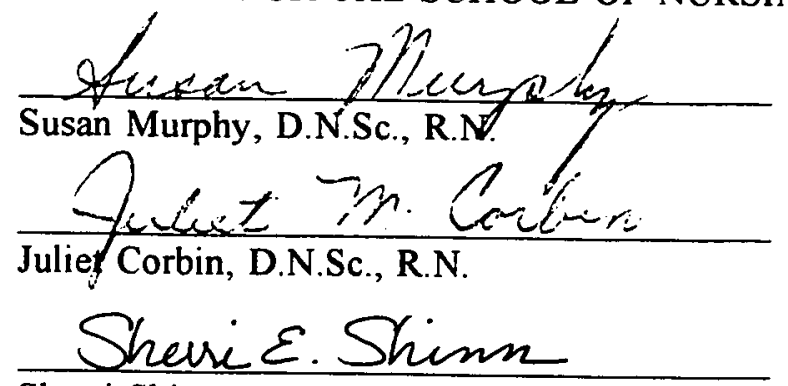

Sherri Shinn, M.S., R.N.

APPROVED FOR THE UNIVERSITY

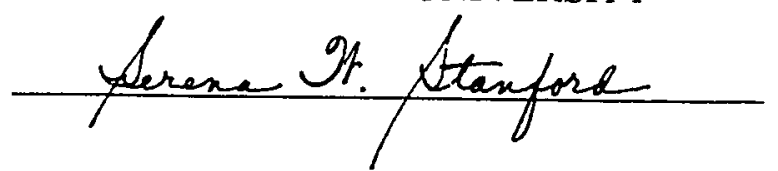


(C) 1995

Christine Marie Derenzi

ALL RIGHTS RESERVED 


\section{ABSTRACT \\ BARRIERS THAT PREVENT \\ OLDER WOMEN FROM PERFORMING BREAST SELF-EXAMINATIONS \\ by Christine M. Derenzi}

This qualitative study examined transcribed interviews for gestalts, or clusters of ideas, about barriers to older women performing Breast Self-Examination (BSE). Unfortunately, no clear cut barriers were uncovered. However, this study did give insight into older women's feelings about breast cancer and performing BSE. The idea clusters discovered in this study were: Lack of Follow Through, Lack of Confidence in Performing BSEs, Breast Cancer Believed to be Hereditary, Health-Seeking Behaviors, Multiple Exposure to Others Diagnosed with Breast Cancer, and Lack of Commitment to Performing BSE. The conclusion drawn from these ideas is that the reason older women do not perform BSE is because of their perceptions about BSE. Unfortunately, these perceptions are formed and reinforced by behaviors of health care professionals.

These findings have implications for health professionals, especially nurses. Hopefully the insights gained from this study will stimulate health care professionals to examine how BSE is taught, discussed, and advocated. 


\section{ACKNOWLEDGEMENTS}

I would first like to acknowledge my three readers: Julie Corbin, Susan Murphy, and Sherri Shinn. With their support and guidance, this study has become a piece of research of which I am very proud.

I would also like to acknowledge the six subjects who participated. They gave me their time and their hospitality. I will always remember their willingness to participate.

I would also like to acknowledge my friends and family. These are the people who for the last year would ask about my thesis and listen when I would lament how difficult a time I was having with it. Their constant support and encouragement helped me to plod through and succeed. A special thanks to my sister, Karen, who transcribed the interviews for me.

Finally, I would like to acknowledge my husband, Damon Tarver, who calmed my nerves, taught me all the features of the computer in order to ease my work, and who hung up more flyers for recruitment of subjects than I'm sure he cares to remember. He patiently took a "back seat" to this thesis many times and his support was unconditional. 
TABLE OF CONTENTS

Page

Chapter

1. Introduction

Purpose of the Study

Statement of Problem

Breast Cancer Statistics

Compliance with Breast Self-Examinations

Research Questions

2. Conceptual Framework 5

Literature Review--Older Women and BSE 7

3. Design 15

$\begin{array}{ll}\text { Subjects } & 16\end{array}$

$\begin{array}{ll}\text { Setting } & 17\end{array}$

$\begin{array}{ll}\text { Human Subjects Approval } & 17\end{array}$

$\begin{array}{ll}\text { Transcription of Interviews } & 18\end{array}$

$\begin{array}{ll}\text { Analysis of Data } & 18\end{array}$

4. Findings 


\section{Chapter}

5. Discussion of Gestalts 26

Limitations of the Study $\quad 34$

Recommendations for Future Research 35

\section{REFERENCES}

APPENDICES
A. Information Sent to Subjects
39
B. Consent Form
C. Interview Guide 


\section{Chapter 1}

\section{Introduction}

Breast cancer is a disease that strikes one out of every ten women living in the United States (Kushner, 1991). In fact, it was predicted in 1992 that in the United States 180,000 women would be diagnosed with breast cancer, and that 46,000 women would die from the disease (Boring, Squires, \& Tong, 1992). What is not known is how many women would have survived had their disease been detected earlier. Breast cancer is a disease in which the survival rate decreases dramatically with late detection. The five year survival rate for localized breast cancer is $91 \%$, with regional spread survival decreases to $69 \%$, and with distant metastases survival decreases to 18\% (American Cancer Society, 1991).

Early detection and treatment of breast cancer increases survival. One early detection method is Breast Self-Examination (BSE)--a free, painless, self-administered intervention regularly performed once per month. BSE promotes early case finding through early detection (American Cancer Society, 1991). However, this practice, performed with the goal of early detection of breast cancer, is simply not being done by many women. In fact, among all women only about $18 \%$ to $36 \%$ examine their breasts monthly and older women are least likely to perform BSEs in spite of being at the greatest risk of developing breast cancer (Maddox, 1991).

The United States government, in Healthy People 2000, listed health care 
objectives for the decade of the 1990s. Among these is the objective that identifies older women (ages 65 to 74) as a special target for breast screening (United States Department of Health, 1991).

\section{Purpose of the Study}

The purpose of this study was to identify barriers that prevent older women from performing Breast Self-Examinations (BSEs). Knowing the barriers to the performance of BSE could be useful to health care providers in planning teaching interventions to increase the practice of BSE among older women.

\section{Statement of the Problem}

\section{Breast Cancer Statistics}

According to the Vital Statistics of California, in 1990, Santa Clara County reported 160 deaths from breast cancer; adjacent San Mateo County reported 113, further north, San Francisco County reported 130; and to the east, Alameda County reported 206 (Department of Health Services, 1992). The same government report attributed 4,311 California deaths to breast cancer at a rate of 28.8 per 1,000 deaths (Department of Health Services).

At the national level, statistics in the Statistical Abstract of the United States reveal the frightening information that the death rate from breast cancer has increased by $50 \%$ in the past 20 years. The national death rate from breast cancer was 29.9 in 1970, 35.9 in 1980, and 45.1 in 1990 (United States Department of Commerce, 1992). 
Every woman is at risk for breast cancer. One risk factor for developing breast cancer is simply being a woman living in the United States (Kushner, 1991). However, the distribution of breast cancer diagnoses is not equally distributed among different age groups of women. Although women 65 and older comprise less than $12 \%$ of the population, they account for more than $40 \%$ of breast cancer diagnoses (Langlands, 1990). One reason older women are especially vulnerable is because the longer a woman lives, the more she is at risk for developing breast cancer (Rosenburg, 1993). The incidence of breast cancer increases dramatically with age. The incidence of breast cancer among women under 50 years of age is 31 per 100,000. After the age of 50, the incidence increases to 331 per 100,000 (Rosenburg).

\section{Compliance with BSES}

Research has shown that while over $90 \%$ of women are aware of BSE, only $15 \%$ perform it monthly (Celentano \& Holtzman, 1983). Other research, surveying registered nurses, revealed that while $99 \%$ of the nurses felt capable of performing a BSE, only $26 \%$ actually practiced it monthly (Heyman, Tyner, Phipps, Cave, \& Owen, 1991). It is frustrating to educators, who try to teach all women to perform BSE regularly, to discover that their colleagues in the health profession are as noncompliant with performing BSE regularly as lay persons. In Dr. Susan Love's Breast Book (1991), Love states that "about 90 percent of [her] patients don't do BSE, and that includes doctors and nurses" (p. 22).

Research has shown that women, both lay persons and health care 
professionals, are not performing BSEs regularly. The question then becomes: How can the frequency of this practice be increased? However, to answer this question one must begin with identification of the reasons why BSE is not performed. The purpose of this research was to identify reasons which hinder the practice of BSE among older women.

\section{Research Questions}

The primary question for this study was: What are the barriers that prevent older women from performing Breast Self-Examinations? An additional query was: What strategies would be helpful in increasing women's compliance with regular performance of Breast Self-Examinations? 


\section{Chapter 2}

\section{Introduction}

In a commentary about the practice of BSE, Humenick lists a number of questions that need to be addressed by nurse researchers. These questions include: "Why don't women practice regular breast self-examinations? Are the reasons different for different age and SES [socio-economic status] groups?" (Humenick, 1992, p. 628). Humenick also suggests that qualitative research strategies might be especially helpful in discovering relevant reasons why women don't perform BSE regularly. Humenick is calling attention to the fact that there are barriers that are preventing women from performing BSE, a health promoting behavior.

\section{Conceptual Framework}

\section{Overview of the Health Promotion Model}

Nola Pender's Health Promotion Model (HPM) is the conceptual framework for this thesis. The HPM provides a framework for studying why some people take action to avoid illness while other people do not (Pender, 1986). It is Pender's belief that there are certain factors that affect a person's likelihood of engaging in healthpromoting behaviors. Pender divides these factors into two major categories: cognitive-perceptual factors and modifying factors.

The cognitive-perceptual factors include perceptions including importance of health, control of health, self-efficacy, definition of health, health status, benefits of 
health-promoting behaviors, and barriers to health-promoting behaviors. The modifying factors include demographic characteristics, biologic characteristics, interpersonal influences, situational factors, and behavioral factors. Pender also defines one other area that she believes affects a person's likelihood of engaging in health-promoting behaviors. Pender calls this area "cues to action." Pender states that these cues can be internal or external. An example of an internal cue is feeling good about oneself as a result of physical activity serving as a cue for continuing to exercise (Pender, 1986). Examples of external cues are conversations with friends or health care workers that promote a behavior. Mass media campaigns such as anti-smoking commercials on television are also forms of external cues to action.

Pender's model states that all of the modifying factors affect a person's perception of the importance of health. The model explains that all of the cognitiveperceptual factors, coupled with cues to action, directly influence a person's likelihood of engaging in health promoting behaviors.

\section{Application of the Health Promotion Model to this Thesis}

Since the purpose of this thesis was discovery, there was no attempt to hypothesize or test why older women were not performing BSEs regularly. Rather, this study sought to discover recurrent themes among the women interviewed as to why they were not performing BSEs regularly.

The conceptual framework was not used to define in advance which particular factors may have been relevant, but rather to suggest the categories of factors that 
influence participation in any health-promoting behavior. The objective was to identify which internal and external factors had an effect upon an individual's participation in this particular health-promoting behavior. Breast self-exam is free and easy to learn. However, research indicates that it is a behavior that a majority of women do not perform on a regular basis. Whereas Pender's model lists kinds of factors a researcher may wish to explore, this study encouraged women to define for themselves which ones were most relevant to them.

\section{Literature Review}

Several quantitative studies have been done in an attempt to discover why women do not perform BSEs. One study (Lierman, Kasprzyk, \& Benoliel, 1991) found that intending to perform a BSE had the strongest correlation to actually performing a BSE. Simply stated, the more persons believed they were likely to perform a BSE, the greater the likelihood they would actually do so (Lierman et al.). This same study found two other interesting correlations. One was between social norms and performing a BSE. This means that if a woman thought a doctor, relative, insurance company, or media campaign felt she should perform a BSE, then a woman would be more apt to perform it (Lierman et al.). The other interesting correlation, a negative one, found that the more a respondent thought breast cancer would affect her life, then the less likely she would be to perform the BSE (Lierman et al.). This finding seems to indicate that women would rather not know something "bad" was happening to them (breast cancer) than take action to help detect breast cancer earlier 
(the performance of a BSE)

One limitation of the study was that it used a questionnaire with a Likert-type scale to discover older women's reasons about why they do not perform BSEs. This questionnaire assumed the reasons "why," and then looked for validation from the women who filled out the questionnaire. Perhaps some major barriers for these women not performing BSEs went undiscovered because of limitations in the questionnaire. The theoretical framework underlying the questionnaire was the Theory of Reasoned Action. This theory incorporates social normative influences and uses a mathematical formula to define the relationships of the major components of the theory (Lierman et al., 1991). The Theory of Reasoned Action was used in order to give numerical values to the responses and run statistical tests.

Another study (Heyman et al., 1991) examined the relationships between a nurse's perceived ability to teach BSE, the nurse's frequency of teaching BSE to patients, and the nurse's frequency of performing BSE. This study also collected data using a Likert-type questionnaire. In the sample of nurses studied, $99 \%$ of the nurses felt capable of performing a BSE; however, only $26 \%$ actually practiced it monthly. The nurses were given a list of twelve "Reasons for not performing BSE" and then were told to choose the number one reason why they did not perform BSEs. The reason chosen by 22 of the 43 subjects was that they "don't think of it" and this was also the main reason these nurses gave for not teaching BSE to their clients (Heyman et al.). 
Another quantitative survey studied the breast cancer screening practices among women living in a retirement community in Pennsylvania. This study found that among 616 women, age 65 and older, $38 \%$ reported having a mammogram in the past year, $53 \%$ reported having a clinical breast exam in the past year, and $39 \%$ reported performing monthly BSEs (King et al., 1993). The researchers used a 49-item survey, combining questions from two different tools and adding some of their own questions. The final tool was guided by the Health Belief Model and the Theory of Reasoned Action. All items were scored on either a 3 or 4 point scale. The women's answers were analyzed comparing the age groups of $65-74$ years, $75-79$ years, $80-84$ years, and $85+$ years. Unfortunately, the researchers state in the first paragraph of the results section that there were no significant differences between age groups with respect to breast self-examination so BSE was eliminated from further analyses (King et al.). Although these researchers discovered that $39 \%$ of their subjects performed BSE regularly and $53 \%$ had a clinical breast exam, and no insight is given as to the reason for the disparity between these two numbers. These findings imply that more women go to a physician (which costs money and requires transportation) to have a breast exam done, than do it themselves for free in their own homes.

Another survey studied the three breast cancer screening practices of mammography, clinical breast exams, and BSEs, and the barriers and facilitators to these screening practices. This study focused on a worksite population of 1,607 women ranging from ages 35 to 68 (Kurtz, Given, Given, \& Kurtz, 1993). 
This study used a newly developed two-part tool, based on the Health Belief Model and Bandura's Self Efficacy Theory. The first part asked for demographic and personal history information. The second part utilized a Likert-type four point scale with questions about barriers and facilitators as they related to mammography, clinical breast exams, and BSEs. In regard to BSE, this study found that $98 \%$ of the women had been taught BSE and $65 \%$ reported performing BSEs; however, only $59 \%$ reported performing a BSE monthly (Kurtz et al.). The researchers, using t-test analysis, found two barriers that were associated with not performing BSEs and two facilitators that were associated with performing BSEs. The two barriers identified were discomfort and lack of knowledge. The two facilitators identified were desire for control over health and perceived efficacy (Kurtz et al.). Again, the barriers and facilitators identified were limited by the choices given to the subjects in the questionnaire. This type of questionnaire assumes the relevance of certain barriers or facilitators and then relies on the subjects' responses to validate or disprove assumptions. Other barriers or facilitators may exist, but if they are not listed in the questionnaire, they will not be discovered in a quantitative study such as this one. The information may be of value, but the question remains: Is the information complete?

Victoria Champion, a nurse researcher from Indiana University, has done several studies regarding BSE. Although her studies have not focused specifically on older women, her findings have given nursing practice some interesting insight into the women's views of breast cancer and BSE. One of Champion's studies dealt with the 
relationship between certain variables from the Health Belief Model and breast cancer detection behaviors (1991). The specific Health Belief Model variables that Champion focused on were perceived susceptibility, seriousness, benefits, barriers, control, and health motivation. The breast cancer detection behaviors that Champion tried to relate to these variables were BSE, mammography, and professional breast examination. This study also used a Likert-type questionnaire that asked statements about benefits and barriers to BSE. In addition, Champion measured confidence in performing a BSE using a 12-item scale based on Bandura's Self Efficacy Theory. With a sample size of over 300 , Champion made discoveries she deemed consistent with discoveries made in past research regarding the practice of BSE. Specifically, Champion found that women who perceive more barriers to BSE are the least likely to practice it. Champion also discovered that women who are uncomfortable with BSE, find it embarrassing, or have difficulty remembering to perform BSE will be less likely to practice the procedure consistently. In her discussion of this particular study, Champion challenges nurses to assess perceived barriers to BSE, levels of confidence in practicing the procedure, and basic knowledge of BSE when planning teaching interventions.

In 1992, Champion had an article published in which she discussed BSE and its role in breast cancer screening. In this study, Champion compared scores regarding attitudes toward breast cancer screening before and after a one-to-one teaching intervention. Champion found that BSE practice can be significantly improved by 
using client-specific attitudinal and teaching interventions. Although in this study Champion studied women age 35 and older, she did call for research regarding BSE to incorporate a protocol that is acceptable to older women and effective in the early detection of breast cancer.

In 1993, Champion published another study related to breast cancer screening behaviors. In this study, which had a sample of 581 women, age 35 and older, Champion sought to refine a Likert-type questionnaire that measured Health Belief Model (HBM) concepts using the context of BSE practice and breast cancer. Champion was trying to help future researchers by testing whether or not the HBM could be a useful tool in assessing BSE behavior. Although Champion felt her tool was a major improvement over earlier work, she felt that further testing was needed to yield an instrument that would be easier to use in a clinical setting. This study leaves open the possibility of developing a more reliable tool to measure feelings about BSE.

Other researchers have addressed the relationship between teaching the practice of BSE and the proficiency of BSE. One study explored the effectiveness of teaching older women BSE using return demonstration on breast models. This study included 87 women over the age of 65 . Using a pretest/posttest design, Maddox (1991) found that return demonstration had a positive effect on the participant's level of confidence. Maddox also reported some interesting findings in her subjective data which included that the women questioned their individual ability to perform BSE, and many were concerned about their ability to distinguish normal from abnormal conditions. Also, 
several women expressed fear of performing an actual self-examination because they were unsure about what to expect or about what to do if they had found a lump (Maddox). Unfortunately, there was no follow-up on these comments in the article because the comments were not the focus of the study. Also, although the study found increased confidence after teaching and return demonstration, Maddox admits that a major limitation of the study was the lack of a control group. Perhaps it was not the return demonstration specifically that increased confidence but that a teaching intervention was done.

One article described a creative method of the use of a rap video to teach BSE. The rap, developed by a nurse in New York, was targeted at teenage girls with the hope that it would be a powerful tool for family members who were unable to read more traditional pamphlets about BSE (Ehmann, 1993). This teaching method was evaluated by 425 teenagers, and all but one responded positively to the rap video (Ehmann). The researcher also found that after 109 middle and high school students viewed the rap video, $78 \%$ indicated that they would encourage their mothers and grandmothers to have a mammogram (Ehmann). This idea certainly promotes the concept of client-specific teaching interventions.

Finally, one study tried to relate three capacities (visual acuity, tactile sensitivity, and mobility of upper extremities) to BSE proficiency in women 65 and older. Although this study was limited by a small sample size of 32 , it does suggest additional areas that might be studied further. The study found that although most of 
the participants had adequate visual acuity and tactile sensitivity, they were unable to perform the visual and tactile components of BSE proficiently (Baulch, Larson, Dodd, \& Deitrich, 1992). The study found that upper extremity range of motion ability was significantly related to the participant's ability to perform the upper extremity mobility component of a BSE (Baulch et al.). This study basically tallied the women's abilities, and then stated how many women out of the thirty could perform the different parts of BSE. An interesting side comment in the discussion part of the article stated that only 32 of the 491 women who lived at the retirement centers (used for the study) consented to participate in the study, which was part of a breast health program in which only 41 women participated (Bauich et al.). The authors commented that it was unclear why more elderly women did not participate (Baulch et al.).

This researcher was not able to find any qualitative studies about the performance of BSEs in older women. Such research strategies could expand our understanding of the barriers that prevent older women from performing BSEs, and also could suggest ways in which health care professionals might increase the frequency of monthly BSEs among women. 
Chapter 3

Methodology

Design

This study used a qualitative exploratory design. According to Burns and Grove (1987) qualitative research "seeks to gain insight through discovering the meanings attached to a given phenomenon" (p. 75). The insights gained by qualitative research can then be used to improve nursing practice. The following is a description of some of the concepts and strategies used by qualitative researchers.

Gestalts. Qualitative researchers sometimes refer to a concept known as "gestalts" by which "knowledge about a particular phenomenon is organized into a cluster of linked ideas, a gestalt" (Burns \& Grove, 1987, p. 76). This study sought to gain knowledge about the barriers older women have to performing BSE the study of transcribed interviews and the linkage of ideas stated by the women. This clustering of ideas led to an increased knowledge of why older women do not perform BSE.

Bracketing. Burns and Grove (1987) explain "bracketing" as a process by which "the researcher suspends or lays aside what is known" and "gets rid of sedimented views" in order to see "all the facets of the phenomenon and the formation of new gestalts" (p. 80). The researcher is expected to "be open and receptive to new perceptions being formed from information received" (Burns \& Grove, 1987, p. 76). This researcher attempted to be open-minded, not allowing preconceived ideas or past 
research dictate the way the interview was conducted or the type of questions that were asked. The researcher was open to new ideas.

Intuiting. Finally, a strategy of qualitative research that was employed in the interpretation of the data was that of "intuiting." This is described by Burns and Grove (1987) as "the process of actually 'looking at' the phenomenon" (p. 80). Burns and Grove insist that during the process of "intuiting" a researcher must focus "all awareness and energy on the subject of interest ... to allow an increase in insight" (p. 80). This researcher emersed herself in the topic of BSE by reviewing related articles, reading books about the topic, and reading and rereading the interview transcriptions in order to discover information that was valuable to women and to the practice of nursing.

\section{$\underline{\text { Subjects }}$}

All of the subjects in this study were females over the age of 65 . All of the subjects lived in a residential apartment complex for senior citizens. Recruitment for this research was done using a letter inviting women over the age of 65 to participate in this study. The letter was taped to the front door of the residents' apartments (see Appendix A). Taping letters or bulletins to residents' doors is a common way to gather and pass along information at this complex. A form was attached to the letter by which persons could volunteer to be contacted to participate in the study.

Residents returned these forms to a pink box placed at the front reception desk of the apartment complex (see Appendix A). The researcher collected the forms from the 
pink box on a regular basis over a two week period. Contact was made with all residents who returned the form and six interviews were completed.

Subjects were selected on the basis that they were willing to sign the consent

form (see Appendix B), were willing to be interviewed, and were willing to have the interview tape recorded. Criteria established for inclusion in this study were that the participant spoke English, was age 65 or older, and did not perform BSE at least once per month.

Setting

Participants in this study were all recruited from the same apartment complex which is located in a major metropolitan area of Northern California. The complex is a retirement housing center for senior citizens and has a population of nearly 200 residents of which over $90 \%$ are female. Residents have their own apartments, which range in size from studio to one-bedroom or two-bedroom apartments. Every apartment has a bathroom and kitchenette. Residents eat meals in a central dining room. Each of the six interviews took place in the participant's living room. The choice of site was made by each participant.

Human Subject Approval

The proposal for this thesis was reviewed by the Human Subjects-Institutional Review Board of San Jose State University. Approval to collect data for this study was received in March, 1994. 
Transcription of Interviews

Analysis of the interviews was done using transcriptions of tape recordings and notes made during the interview. The researcher contracted with her sister, Karen Derenzi (1989 San Jose State University Graduate, Journalism), to transcribe all tapes. During transcription, all identifying information about the subject was removed. Analysis of Data

Data were analyzed by examining each word of the transcribed interviews and searching for gestalts among the women interviewed. It was with guidance of an expert in the field of qualitative study, Dr. Juliet Corbin, that the researcher was able to see beyond the surface of what was said by the women. Six gestalts were discovered and are discussed in the next chapter. 


\section{Chapter 4}

\section{Findings}

Introduction

All of the interviews were conducted using the same interview guide (see Appendix C). Through analysis of the transcribed interviews, the researcher discovered areas that can be called "gestalts" or clusters of ideas. These gestalts will be discussed in this chapter. They include: Lack of Follow Through, Lack of Confidence in Performing BSEs, Breast Cancer Believed to be Hereditary, Heal thSeeking Behaviors, Multiple Exposure to Others Diagnosed with Breast Cancer, and Lack of Commitment to Performing BSE.

Lack of Follow Through

Although five of the six women reported receiving varying degrees of BSE instruction, none followed through to clarify or receive more information. One woman who discussed having no instruction at all, did not seek out information until the opportunity was presented to participate in this study.

Subject Two, an emerita professor at a large private university, stated, "I don't know ever getting any particular instruction, except reading a pamphlet, until I was post menopausal." She then stated that both her internist and her gynecologist recently taught her about BSE. However, even with this education on BSE from various sources (written and verbal) she admitted "forgetting" about BSE. The subject, who 
had earned a Master's degree and who is currently taking self-improvement courses, never reported seeking information about BSE on her own.

Three of the subjects reported participating in a group teaching project on BSE. After this initial group teaching, none followed-up on the teaching. Subject Three recalled participating in a group teaching session. When asked what she remembered being taught, she stated, "I remember she had a breast model. It was about ten years ago." Subject Four also reported going to no other teaching sessions and not seeking more information after the initial teaching session. Subject Four recalled that she was taught "probably [on] occasions when there was a group together" and also stated her gynecologist "would mention it." Both of these women did not perform BSE at all. Subject Six remembered attending a BSE class at the retirement community where she lives. She stated that she could feel the lumps on the models (used for demonstration at the class) but that she "couldn't relate it to [her] own breasts" and that she "didn't know what [she] was feeling for." Subject Six went to one class on BSE and did not feel confident about her ability to perform BSE, so she gave up on performing BSE. She did not seek more information or instruction, even though there is a nursemanaged health center available year round in the building where she lives.

None of the participants reported taking the initiative to seek information on BSE. Those who did receive BSE information never followed through to clarify or ask for more help. It is unclear from their statements why the women did not follow through or take the initiative to learn about BSE although the following categories may 
provide some insight into this question.

\section{Lack of Confidence in Performing BSEs}

Two of the subjects verbalized a lack of confidence in their ability to perform BSE. Subject Two described herself as having "fibrous breasts" and that she "can't tell exactly" what to feel for in her breasts. Subject Two admitted "it's hard for me." Subject Six described herself as having "so much scar tissue that I don't know what I'm feeling." Subject Six reported that because she did not know what she was feeling, she "hadn't tried it for about a year." However, Subject Six did not say that she sought further instruction which might have increased her confidence.

These two participants demonstrate a lack of confidence in their own skill of performing BSE. The women discussed not knowing what they were feeling in their breasts. What was especially noteworthy was that the lack of confidence led to the women simply giving up on performing BSE rather than finding ways to learn more about BSE.

Breast Cancer Believed to be Hereditary

Several subjects reported that breast cancer was not a threat to them because it was not in their family histories. This was given as a reason for not doing BSE. Subject Four admitted, "I've always been very relaxed about it [breast cancer] because it hasn't shown up in my strain of family." Subject Three stated, "I don't think I have cancer; it's not in my family." Subject One stated, "On my husband's side they get cancer. My daughter had cancer, too." Subject Four, whose husband's sister died of 
breast cancer, stated, "I often worry about my daughter, but I was told--and I don't know how true it is--that it's through the mother's side of the family."

In contrast to the statements describing family histories void of breast cancer were statements made by a subject who did have a family history of breast cancer. This woman felt she was at risk for breast cancer. Yet, the risk was not perceived to be great enough to motivate her to perform a BSE. Subject Two stated: "My aunt had breast cancer and my father's sister--she was older, so it's quite possible it could happen."

It was clear that these subjects perceived a definite tie between the risk of a breast cancer diagnosis and the incidence of breast cancer in one's family. The women who did not perceive a threat of breast cancer, due to family history of no breast cancer, used this information to justify not performing BSE. Subject Two, who felt that "it's quite possible it could happen" also stated that she "forgets" about BSE. Health Seeking Behaviors

All of the women displayed health-seeking behaviors unrelated to BSE. All of the subjects were seeing physicians on a regular basis. Some were seeing physicians for medical problems, while others were seeing physicians for preventative care. Three of the women reported having a clinical breast exam (CBE) which is a breast exam performed by a health care professional on a patient. One of these three, and two others who did not report having a CBE, did have a mammogram. This shows that while the women participated in forms of breast cancer screening, they did not 
perform the BSE screening procedure.

All of the subjects responded to the question asking them what they would do if they found a breast lump by reporting they would consult a physician. Regardless of whether or not the subject knew of positive or negative outcomes to the diagnosis of breast cancer, all of the women felt certain that they would call their physician if they found a breast lump. Specifically, when the women were asked what they would do if they found a breast lump, Subjects One and Three both stated, "I'd go to the doctor." Subject Two stated, "I'd immediately get help. I would call the doctor and make an appointment now." Subject Four stated, "I would go to my doctor." Subject Five stated, "I wouldn't know what to think. I would do what my doctor said." Subject Six stated that she had actually had breast cancer and had a lumpectomy performed in 1986. The women all knew that intervention by a physician was needed if a breast lump was found.

It is clear that although these women do not perform BSE, they are not adverse to seeking health care or to obtaining other types of breast cancer screening. One difference between a BSE and CBE/mammogram is that doing BSE is the responsibility of the individual and a $\mathrm{CBE} / \mathrm{mammogram}$ is the responsibility of a health care professional.

Multiple Exposure to Others Diagnosed with Breast Cancer

Subject Two made some especially candid comments about breast cancer: "I just think it's a devastating thing anyhow." Subject Two spoke of "four or five" 
women she knew well who have been diagnosed with breast cancer. She discussed how breast cancer has affected her friends:

"So I've been closely involved and I know what it can be like and how dreadful it is. It's bad enough for anybody but when it's someone so young, it's just a shame."

Subject Five's mother died of breast cancer and Subject Six had breast cancer herself. Even with breast cancer this close, Subject Five stated she was never taught about BSE and Subject Six had tried BSE but gave up because she "didn't know what [she] was feeling for."

All of the subjects reported knowing women who had been diagnosed with breast cancer. From mothers to sisters-in-law to friends to students, these women had seen breast cancer victims. Nevertheless, first hand experience was insufficient motivation for the women to practice BSE on a regular basis.

\section{Lack of Commitment to Performing BSE}

Not one of the subjects committed to performing a BSE on a regular basis. Subject One stated, "I'll try. It sounds simple." Subject Three stated that "I'd do it each month on my birthday day", yet did not commit to perform a BSE regularly. Even after discussing breast cancer and being taught about BSE, not one subject committed to performing BSE regularly.

\section{Conclusion}

The frustrating conclusion that can be drawn from this data is that there is no clear-cut barrier to BSE. There is no magical key to unlock the dilemma of why older 
women do not perform BSEs. One can almost see the women "shrugging off" BSE as they make statements such as "it's not in my family" or "it's hard," or that they have CBEs and mammograms done and feel that this is sufficient.

Not one woman asked for follow-up instructions or thought of an aide that would help her to remember. They simply made statements along the line of what Subject One stated, "I'm sure it's not that difficult that I can't remember." Yet Subject One made no commitment to performing BSE. It was as if the women did not want to bother with performing BSE.

There is much that can be inferred from the ideas the subjects presented. Chapter Five includes a discussion of the findings presented in this chapter and states the implications of this information for nursing practice. 


\section{Chapter 5}

\section{Discussion}

\section{Introduction}

The researcher began this study with the intention of interviewing older women to discover barriers that prevented women from performing BSEs on a regular basis. Through analysis of six interviews, six gestalts were identified. These were: Lack of Follow Through, Lack of Confidence in Performing BSEs, Breast Cancer Believed to be Hereditary, Health-Seeking Behaviors, Multiple Exposure to Others Diagnosed with Breast Cancer, and Lack of Commitment to Performing BSE.

This chapter will discuss several areas related to this study. First will be a discussion of the gestalts and how they relate to nursing practice and/or to the selected conceptual framework: Pender's Health Promotion Model (HPM). After this discussion the limitations of this study will be presented. Finally, the last section of this chapter will list recommendations for future research.

\section{Discussion of Gestalts}

Lack of Follow Through. This theme was disturbing to the researcher because it shows a passiveness on the part of women toward the performance of BSE. No woman verbalized a proactive stance by seeking information about BSE. Even a woman who was taking self-improvement courses took no active stance toward educating herself about BSE. 
This theme of the Lack of Follow Through seems to have a great implication for nursing. The data suggests that nurses can't expect their female patients to proactively seek out information about BSE. Nurses must take the initiative to teach patients about BSE. However, as discussed in the literature review, nurses are not teaching their female clients about BSE. In a study that included 102 nurses total (in both a control and experimental group), only 15 nurses reported teaching BSE at least occasionally (Heyman et al., 1991). The top two reasons given by the nurses for not teaching BSE was "don't think about it" and "not enough time" (Heyman et al.).

Clients are not asking for information about BSE, and the nurses either do not think about teaching it or do not have the time to teach it. Perhaps a major barrier to the performance of BSE is that no one talks about it. Health care professionals are simply not stressing to their patients the importance of performing BSE, nor are they role modeling it by their own behavior. Think of what compliance to BSE would look like if every hospital and clinic had as a policy the teaching about BSE every time a woman visited that institution. Compliance to BSE would look very different if nurses remembered to teach $\mathrm{BSE}$ to their clients.

The lack of follow through can be related to the external cues to action portion of the HPM model. These cues supporting health promotion behavior appear to be lacking in the area of BSE. A study that noted only 15 of 102 nurses taught BSE occasionally indicates that at least at the institution where the study was performed, the nurses were not giving cues to the patients about performance of BSE 
(Heyman et al., 1991). Not only are women showing a lack of follow through, but at least the findings of that study suggest that nurses are not following through either. If a hospital or clinic instituted a policy directing the teaching of BSE to all female patients then external cues to action might increase.

Lack of Confidence in Performing BSEs. This theme is related to the theme just discussed. It would seem that confidence in performing any task increases if a person either is taught more about the task or can practice the task more. If the women interviewed showed a lack of following through on gathering information, a lack of practicing the task, and did not seek help in increasing their proficiency in performing BSE, then it seems impossible for them to become confident in the skill.

This, too, has implications for nursing practice. If patients are taught about BSE more consistently, and allowed to practice under the guidance of a health care professional, ther their confidence might increase. An increase in confidence may lead to increased performance of BSE on a more consistent basis. Again, the barrier to BSE may simply be that since no one is talking about it, no one is learning about it to the point of feeling confident about its performance.

This theme seems to relate to the HPM concept of self-efficacy. Pender believes that perception of self-efficacy is related to the likelihood of engaging in a health-promoting behavior. The model states that if people believe they can do a behavior, they are more likely to engage in that behavior. If people do not believe they can do a behavior, then they are less likely to engage in that behavior. Certainly, 
these women seemed to lack an "I can do it" attitude toward BSE.

Breast Cancer Believed to be Hereditary. This theme demonstrates a need for clarification. It is believed that hereditary breast cancer occurs in $5 \%$ to $7 \%$ of all breast cancer diagnoses (Love, 1991). Therefore, a vast majority of breast cancer diagnoses are not related to hereditary factors. Research shows that a risk factor for breast cancer is being a woman living in the United States (Kushner, 1991). Clearly, all of the women interviewed live in the United States. While the participants were accurate in identifying heredity as a risk factor, the participants did not discuss any other risk factors for breast cancer. The women did not discuss any knowledge of the fact that heredity plays a part in less than $10 \%$ of the breast cancer diagnoses. Since over $90 \%$ of breast cancers are related to risk factors other than heredity, it is important for women to understand that they are at risk for breast cancer even if their ancestors did not have breast cancer.

The implication for nurses is that they should provide clear and fact-based information to women about breast cancer. The women who use the fact that breast cancer is not prevalent in their families as a reason for not to performing BSE should be given factual information about risk factors and the present epidemic of breast cancer. It should be made clear to women that while family history of breast cancer is a factor in $5 \%$ to $7 \%$ of diagnoses, it is clearly not the only risk factor.

Health-Seeking Behaviors. It was fascinating to this researcher to hear the amount of health-seeking behaviors discussed by the women who were interviewed. 
No one was adverse to obtaining health care, to seeing the doctor, or even to doing other types of breast cancer screening procedures (CBE or mammography). Yet, these women did not perform BSE. Perhaps women do not see themselves as being "good enough" at performing BSE and this affects their motivation. They may perceive health care providers and the other forms of breast cancer screening as a safety net that they can fall back upon rather than relying upon themselves to detect a breast lump. These women might see breast exams as the responsibility of health care professionals rather than their responsibility. Perhaps, as some of the research has shown, women are simply afraid of what they will find (Maddox, 1991). They simply do not want to know.

The implications for nursing are very intricate for this theme. Perhaps, nurses are perpetuating the feeling that breast exams are not the responsibility of the lay person by not teaching and promoting BSE. Clients may see health care professionals as the "doers" and themselves as the "passive participants." In health care settings much control is taken away from patients. Maybe women are so used to giving away responsibility for their health care to professionals that it is easy for them to give up BSE performance, an activity women see as difficult to do anyway. The women may feel that CBEs and mammograms are sufficient. Perhaps, not enough emphasis is being placed on the woman's role in breast screening--BSE.

This theme of health-seeking behaviors also relates to the HPM concept of perceived control of health in two ways. The first way is that the women interviewed 
see themselves as having control over their health evidenced by their display of so many health-seeking behaviors. The manner in which they exert this control is by taking advantage of what is offered to them by their physicians. The women interviewed certainly did not display a fatalistic attitude toward disease processes. The second way the concept of perceived control of health relates to health-seeking behaviors is that women have chosen to give control of breast exams to the health care professionals, rather than seizing the control themselves. The conclusion that can be drawn from these statements is thus. The likelihood that women will engage in the health-promoting behavior of CBE or mammography is high because they perceive they have the control to make an appointment and are able to pay for that intervention. The likelihood that women will engage in the health-promoting behavior of BSE is low because women do not see themselves as having control over their performance that behavior. The reasons they do not perceive that control are Lack of Follow Through and Lack of Confidence.

Multiple Exposure to Others Diagnosed with Breast Cancer. This theme exemplifies the large incidence of breast cancer in this country. All of the women interviewed knew of other women who had breast cancer; one of the women had a history of breast cancer. Nevertheless, that knowledge did not motivate the women to perform BSE.

The implication for nurses is that providing statistics about the prevalence of breast cancer does not motivate performance of BSE. It simply is not enough to say 
to the women that the threat is real or to point out they know of women who have had breast cancer. Furthermore, having had breast cancer oneself does not appear to provide sufficient motivation for doing BSE regularly. Perhaps another major barrier is denial. Women may not want to believe that it could happen to them, and may not believe that they possess the ability to detect a cancerous growth. Maybe women see the practice of BSE as a waste of time because either they have never heard of a woman detecting breast cancer through BSE, or they simply do not believe it will work for them. To this researcher is seems that the first reason is a possibility. Even though women have multiple exposure to other women who have been diagnosed with breast cancer, they do not hear of women who detect breast cancer by performing BSE.

This theme could relate to the HPM concept of perceived benefit of healthpromoting behavior. It could be that the women do not see the benefit of BSE performance because they have not heard of women who have discovered breast cancer by using this form of screening. They have indeed heard of breast cancer being detected by mammography. If women do not see a behavior as beneficial, they may not be motivated to perform it.

Lack of Commitment to Performing_BSE. Women do not commit to performing BSE. They do not feel confident in performing BSE, they do not see its importance in breast cancer screening, and they probably question its value as a method of detection. One conclusion of this study is that a major barrier to BSE 
could be that the perceptions held by women about BSE are reinforced by health care professionals. How can nurses expect women to commit to performing an activity that, as one study showed, nurses themselves do not think about and do not take the time to stress as important (Heyman et al., 1991). It is contradictory to state how important BSE is and how it should be done every month, while at the same time is an activity that a very few nurses discuss with their patients. Maybe it seems incongruent to say to women that BSE (an intervention performed at home by a lay person) has the same importance in detecting breast cancer as a mammography (done by a machine that costs tens of thousands of dollars and only needs to be done once a year).

The implication for nurses is that the profession of nursing needs to make a commitment to BSE. The "story" needs to be that BSE is important, relevant enough for nurses to teach it to their patients and for hospitals to make teaching it a priority. The United States government saw the importance of breast screening when women age 65 to 74 were chosen as a special target for breast screening for the decade of the 1990s (U.S. Department of Health, 1991). The decade of the 1990s is almost half over and the changes made for this target group are not evident. What changes actually have been made by hospitals, clinics, physicians, and nurses? This study has given nursing a glimpse of what women are feeling and thinking about BSE. The challenge now would be for nurses to take action by planning client specific teaching interventions based on those feelings and thoughts. 


\section{Limitations of the Study}

A major limitation of this study was that the sample was both small (only six women agreed to participate) and self-selected. If a larger, more heterogenous sample had been interviewed, broader insights might have resulted. Perhaps women who volunteer to participate in studies hold different views than women who choose not to be involved.

The sample also knew that the study question was related to BSE, so that could affect the way they answered the questions. Even the half-hearted statements about "trying" BSE could have been made to please the researcher. Certainly, the responses of the women to the questions could have been influenced simply by the researcher asking the questions. The women may have responded in a manner that they thought the researcher wanted to hear, rather than stating their true feelings.

The ability to generalize the information from the study is limited by the fact that all of these women lived independently, had a stable economic status, and had health insurance. This study is also limited by the fact that all participants were Caucasian and live in the same retirement apartment complex. The fact that these women all had health insurance may affect their motivation to seek medical care. Although all of the women stated they would immediately seek a physician if a breast lump was found, all of the women had health insurance. All of the women presented health-seeking behaviors, but the women's stable economic status and possession of health insurance may have motivated that response. 
Another limit of this study is that the interviews took place during the month of October. October is Breast Cancer Awareness Month in the United States. This led to stories in the newspaper being published about breast cancer, and items about breast cancer being shown on the television. Also, a bulletin board at the retirement complex where the subjects live had information on it about breast cancer and BSE. This influx of information about breast cancer and BSE may have had an effect on the responses given by the women interviewed.

\section{Recommendations for Future Research}

One recommendation for future research is that this study be replicated with a larger, more diverse group of older women. It would be interesting to interview the same age group of women, but increase the sample size to include women of a variety of cultural and economic backgrounds. It would be valuable to interview women who had no health insurance. It would be most interesting to discover if the desire to seek medical attention when a breast lump is found exists among women who do not have insurance. Attitudes may be different among women who do not have insurance: Would these women see preventative, free interventions (BSE) as more worthwhile or would they have a more fatalistic attitude toward disease processes? Also, women of different cultures, who have different views toward health and medical care may perceive BSE differently. If a woman were a member of a culture that viewed health as "God's will" she might have different ideas about performing BSE than women who do not hold that belief. Also, beliefs about touching one's own body vary among 
cultures, and this could affect a woman's motivation to perform BSE.

The belief about breast cancer being hereditary could be further explored. The information needs to be made clear to women, especially information regarding breast cancer risk factors, and what percentage of breast cancer diagnoses are believed attributable to heredity. A woman that believes her family history is free of breast cancer might not be motivated to perform BSE. If this is a common practice among women, then perhaps a media campaign about the risk factors for breast cancer should occur. 


\section{References}

American Cancer Society. (1991). Cancer facts and figures. Atlanta: American Cancer Society.

Baulch, Y. S., Larson, P. J., Dodd, M. J., \& Deitrich, C. (1992). The relationship of visual acuity, tactile sensitivity, and mobility of the upper extremities to proficient breast self-examination in women 65 and older. Oncology Nursing Forum, 19 , 1367-1372.

Boring, C. C., Squires, T. S., \& Tong, T. (1992). Cancer Statistics, 1992, 42, 19-38.

Burns, N., \& Grove, S. K. (1987). The practice of nursing research: Conduct, critique and utilization. Philadelphia: Saunders.

Celentano, D. D., \& Holtzman, D. (1983). Breast self-examination competency: An analysis of self-reported practice and associated characteristics. American Journal of Public Health, 73, 1321-1323.

Champion, V. L. (1991). The relationship of selected variables to breast cancer detection behaviors in women 35 and older. Oncology Nursing Forum, 18, 733-739.

Champion, V. L. (1992). The role of breast self-examination in breast cancer screening. Cancer supplement, $\underline{69}$, 1985-1991.

Champion, V. L. (1993). Instrument refinement for breast cancer screening behaviors. Nursing Research, 42, 139-143.

Department of Health Services. (1992). Vital statistics of California 1990 Sacramento, CA: State of California Health and Welfare Agency.

Ehmann, J. L. (1993). BSE rap: Intergenerational ties to save lives. Oncology Nursing Forum, 20, 1255-1259.

Heyman, E., Tyner, T., Phipps, D., Cave, L., \& Owen, D. C. (1991). Is the hospital setting the place for teaching breast self-examination? Cancer Nursing, 14, 35-40. 
Humenick, S. S. (1992). Commentary by Humenick [Commentary of Self-esteem and the practice of breast self-examination]. Western Journal of Nursing Research, $14,618-631$.

King, E. S., Resch, N., Rimer, B., Lerman, C., Boyce, A., \& McGovern-Gorchov, P. (1993). Breast cancer screening practices among retirement community women. Preventive Medicine, 22, 1-19.

Kurtz, M. E., Given, B., Given, C. W., \& Kurtz, J. C. (1993). Relationships of barriers and facilitators to breast self-examination, mammography, and clinical breast examination in a worksite population. Cancer Nursing, 16, 251-259.

Kushner, R. (1991). If you've thought about Breast Cancer... (Available from Bay Area Breast Cancer Network, 4010 Moorpark Avenue, Suite 105-B, San Jose CA 95117).

Langlands, A. O. (1990). Breast cancer. In F. I. Caird \& T. B. Brewin (Eds.), Cancer in the Elderly (pp. 87-95). Boston: Butterworth.

Lierman, L. M., Kasprzyk, D., \& Benoliel, J. Q. (1991). Understanding adherence to breast self-examination in older women. Western Journal of Nursing Research, 13, 44-66.

Love, S. (1991). Dr. Susan Love's breast book. Reading, MA: Addison-Wesley.

Maddox, M. A. (1991). The practice of breast self-examination among older women. Oncology Nursing Forum, 18, 1367-1371.

Pender, N.J. (1986). Health promotion in nursing_practice (2nd ed.). Norwalk, CT: Appleton \& Lange.

Rosenburg, A. (1993). Breast cancer: Options for older patients. Geriatrics, $\underline{48}$, 9-13.

United States Department of Commerce. (1992). Statistical abstract of the U.S. 1992. Washington, D. C.: Economics \& Statistics Administration.

United States Department of Health and Human Services Public Health Service. (1991). Healthy People 2000 (DHHS Publication No. PHS 91-50212). Washington, D. C.: U.S. Government Printing Office. 


\section{APPENDIX A}

Information Sent to Subjects 
Dear Chai House Resident--

I NEED YOUR HELP! My name is Christine Derenzi, and I am a Graduate Student at San Jose State University as well as a Nurse. I am writing a thesis regarding why older women do not perform Breast SelfExams regularly. If you do NOT perform Breast SelfExams at least once per month and would like to talk to me about the reasons why, please call me at 408-269-9501 or leave a message for me in the ---Health Center.

The interview session (about one hour) will be followed by a teaching session about Breast Self-Exam. Thank you so much!

Sincerely, 
APPENDIX B

Consent Form 


\title{
AGREEMENT TO PARTICIPATE IN RESEARCH AT SAN JOSE STATE UNIVERSITY
}

\author{
TITLE OF RESEARCH: BARRIERS THAT PREVENT OLDER WOMEN FROM \\ PERFORMING BREAST SELF-EXAMINATIONS \\ RESPONSIBLE INVESTIGATOR: Christine Derenzi, R.N. \\ HUMAN SUBJECTS APPROVAL: March 1994
}

I have been asked to participate in a research study that is investigating barriers that prevent older women from performing Breast Self-Examinations (BSEs) regularly. I am eligible for this study because I am a female, age 65 or older, and do NOT perform a Breast Self-Examination (BSE) on myself at least once per month. The purpose of this study is to help us understand those barriers that prevent older women from regularly performing BSEs. The findings of this study could potentially benefit older women in the future by helping health care professionals understand the special situations of older women that prevent these women from regularly performing BSE.

$I$ understand that:

This study will take place in the form of a tape recorded interview at my apartment. The nurse researcher will come to my apartment once to interview me and then follow the interview with a teaching session about BSE. Each interview will last approximately one hour and the teaching session will last approximately one-half hour.

At any time I may listen to the tape that is being recorded. I understand that the tapes will be transcribed and that during transcription, all identifying names will be removed. There is a potential risk of loss of privacy. Confidentiality will be protected as far as possible under the law. Numbers will be used for storing and analyzing the data. I understand that the tapes will be kept in a locked safe and after the research study is completed, the tapes will be destroyed.

There may be a risk of potential embarrassment or discomfort during the interview process, or potential for remembering difficult times with the discussion of breast cancer. Participation is voluntary. I may decline to answer any question or decline to participate in any part of this study. I may withdraw at any time without prejudice to my relationship with San Jose State University.

initials 
Any questions about my participation in this study will be answered by Christine Derenzi, R.N. at (408) 269-9501. If I have any comments or complaints about participation in this study and want to talk with someone other than the researcher, I may contact Dr. Bobbye Gorenberg (Nursing Department Chairperson) at (408) 924-3132, or Serena Stanford, Ph.D. (Associate Academic Vice President for Graduate Studies) at (408) 924-2480.

I have received a copy of this consent form.

HAVING READ THE INFORMATION PROVIDED ABOVE, I HAVE MADE A DECISION WHETHER OR NOT I MAY PARTICIPATE. MY SIGNATURE INDICATES THAT I AM WILLINGLY GIVING CONSENT TO PARTICIPATE IN THIS STUDY.

Subject

Date

Christine Derenzi, R.N., Researcher

Date 
APPENDIX C

Interview Guide 
Interview Guide

--Introduce yourself and share minimal background information

--State "I need to ask a few preliminary questions"

--Are you age 65 or older?

--Do you know what Breast Self-Exam (BSE) is?

if yes: ask, do you perform Breast Self-Exam at least once per month?

if no: explain briefly what Breast Self-Exam is, and ask question again

--If subject states they do indeed perform BSE, but not once per month, ask:

how often would you say you perform it?

why do you perform BSE less than once per month?

do you remember being taught about BSE?

who taught you about BSE?

what did they teach you about BSE?

could you show me how you perform your BSE?

what helps you remember to perform your BSE?

what do you think would help you to remember to perform your BSE at least once per month?

--If subject states they do not perform BSE at all, ask:

do you remember being taught about BSE?

who taught you about BSE? 
Interview Guide (page 2)

what did they teach you about BSE?

what do you think would help you perform BSE at least once per month?

--Other interview questions, regardless of how often a subject performs BSE:

What would you do if you found a breast lump?

Have you ever found a breast lump? If yes, what happened after you found it?

What kind of treatments do you know about for breast cancer?

Have you ever been treated for breast cancer? If yes, what was your experience?

Do you know anyone who was treated for breast cancer? What happened to that person? 